\title{
Presence and Distribution of the Vascularisation of Aortic Media in Some Mammals
}

\author{
Flavia RUXANDA ${ }^{1}$, Aurel DAMIAN ${ }^{1}$, Vasile RUS ${ }^{1 *}$, Adrian GAL ${ }^{1}$, Cristian MARTONOS ${ }^{1}$, Dalma CSIBI ${ }^{1}$, \\ Cristian RAŢIU ${ }^{2}$, Viorel MICLĂUŞ ${ }^{1}$ \\ ${ }^{1}$ University of Agricultural Sciences and Veterinary Medicine Cluj-Napoca, Romania. \\ ${ }^{2}$ University of Oradea, Romania. \\ *Corresponding author: vasilerus2002@yahoo.com
}

Bulletin UASVM Veterinary Medicine 72(2) / 2015,

Print ISSN 1843-5270; Electronic ISSN 1843-5378

DOI:10.15835/buasvmcn-vm: 11374

\begin{abstract}
It is well known that in the large caliber vessels, the nutrition of the wall differs in the internal part in comparison to the external one. In the present study we assessed the presence and distribution of vascularisation of aortic media in 3 species: lamb, rabbit and chinchilla. Samples were harvested from a group of 3 animals for each species. After histological processing, we stained the sections and assessed the presence and distribution of vasa vasorum. In lamb, blood vessels were present in the media of the cranial aortic segments (with a larger caliber), and starting with abdominal descending aorta they were absent. In rabbit and chinchilla, blood vessels were not present in tunica media. The current study shows that vasa vasorum are present only in tunica media of arteries exceeding a certain caliber.
\end{abstract}

Keywords: chinchilla, lamb, rabbit, vessel

\section{INTRODUCTION}

Aorta is the main artery of the body and it arises from the left ventricle of the heart (Damian, 2007). It falls under the elastic arteries category and its media is formed out of 40 to 60 elastic lamellae (Miclăus, 2012). The nutrition of the vascular wall differs according to the distance from the vascular lumen. Intima and the internal part of the media are avascular (Raica et al., 2004), thus the nutrition takes place through difussion of the luminal nutrients. On the other hand, adventitia and the external part of media present vasa vasorum which ensure the nutrition of these areas. In their study, Wolinsky and Glagov (1967) show that in the internal part of the media, between the first 29 lamellae, there are no blood vessels. They also affirm that the number of elastic lamellae increases with age and that there are differences regarding the number of elastic lamellae in tunica media and the size of the animal.

\section{AIMS AND OBJECTIVES}

We aimed to study the presence and to compare the distribution of vasa vasorum in 3 mammal species: lamb, rabbit and chinchilla.

\section{MATERIALS AND METHODS}

We harvested samples from the aortic arch, thoracic descending aorta and abdominal descending aorta from 3 lambs, 3 rabbits and 3 chinchillas. The fragments were fixed in Stieve's solution, embedded in paraffin and sectioned at a $5 \mu \mathrm{m}$ thickness. In order to confer contrast to the sections we stained them with Goldner's trichrome.

\section{RESULTS AND DISCUSSION}

Examining the aortic arch sections in lamb, we noticed that there are different caliber vessels (from capillaries to arterioles) present in the structure of the media. The distribution of the 


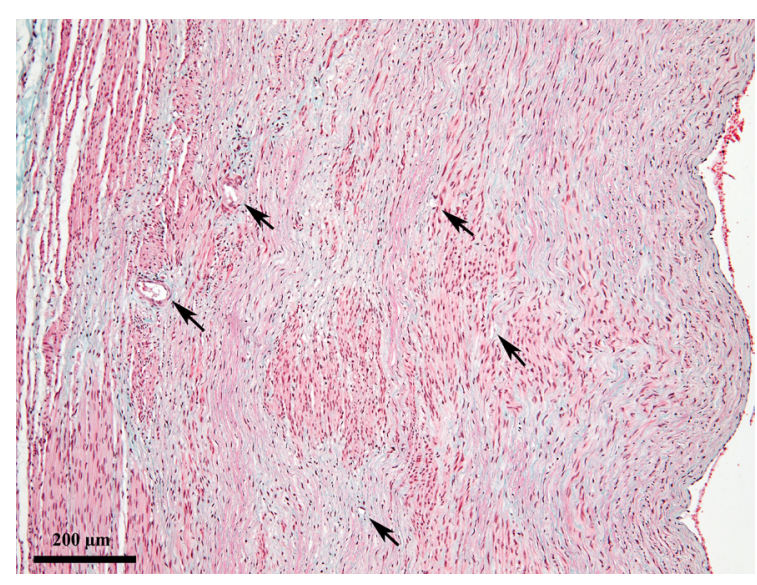

Fig. 1. Aortic arch (lamb): black arrow - blood vessels (Goldner's trichrome)

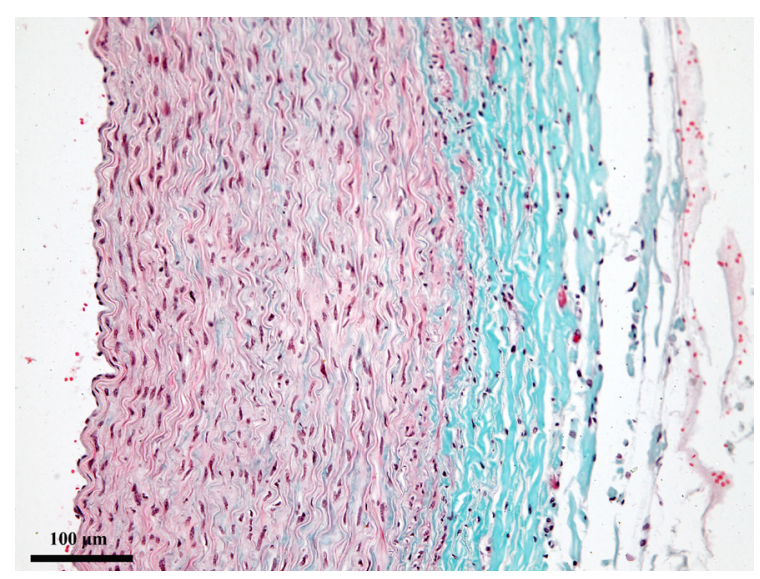

Fig. 3. Descending abdominal aorta (lamb) (Goldner's trichrome)

vessels is not uniform: the larger caliber vessels are encountered in the external half of tunica media. In the media of the thoracic descending aorta, the vessels are still present, but in significantly smaller numbers in comparison to the aortic arch. Regarding their caliber, there is an obvious decrease in comparison to the previous segment. In the abdominal descending aorta, the blood vessels literally disappear from tunica media's structure. Examining the arterial segments from rabbits and chinchillas, we did not observe any blood vessels in the structure of the media.

\section{CONCLUSION}

Numerically, the media of the aortic arch in lambs contains relatively well represented blood vessels, from capillaries to relatively large arterioles, which significantly decrease in both number and size in the thoracic descending

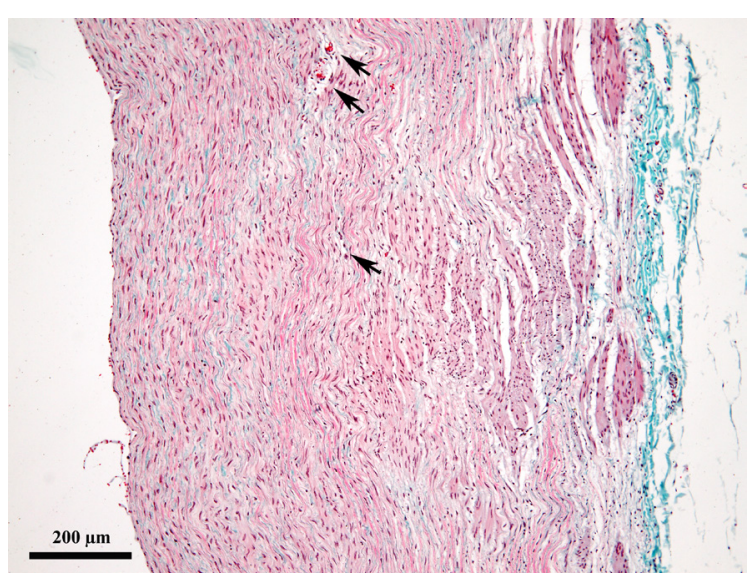

Fig. 2. Thoracic descending aorta (lamb): black arrow - blood vessels (Goldner's trichrome)

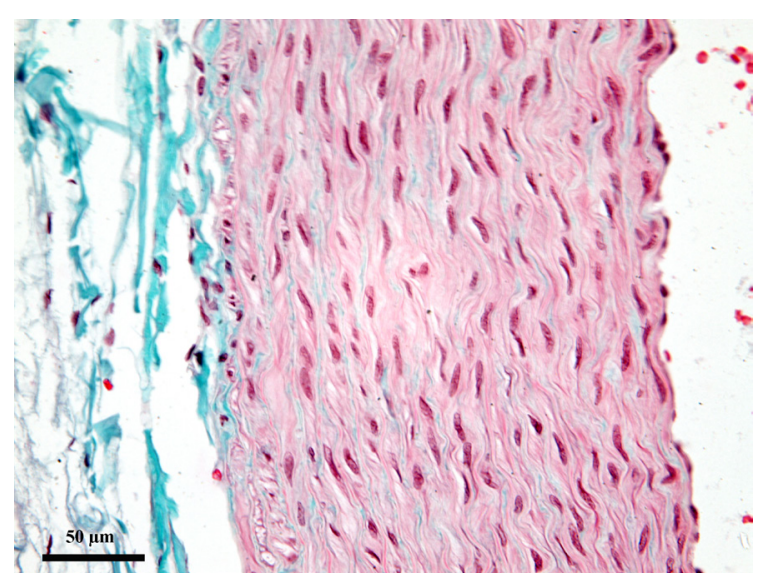

Fig. 4. Aortic arch (rabbit) (Goldner's trichrome)

aorta and are absent starting with the abdominal descending aorta. In rabbits and chinchillas, no blood vessels were highlighted in the media of the studied arterial segments, which shows that the vessels appear only in the media of arteries exceeding a certain thickness, therefore they are not present in all mammal species.

\section{REFERENCES}

1. Damian A (2007). Anatomie Comparată, Sistemul Cardiovascular. AcademicPres, Cluj-Napoca.

2. Miclăuș V (2012). Histologie specială și embriologie generală, Editia a II-a. Risoprint, Cluj-Napoca.

3. Raica M, Mederle O, Căruntu ID, Pîntea A, Chindris AM (2004). Histologie teoretică și practică. Brumar, Timișoara.

4. Wolinsky H, Glagov S (1967). Nature of species differences in the medial distribution of aortic vasa vasorum in mammals. Circulation Res 20:409-421. 